\title{
Clinical Profile of Epistaxis in Sokoto: A 12-Year Analysis
}

\author{
Aliyu Daniel*, Yikawe Semen Stephen \\ Department of Ear, Nose and Throat, Usmanu Danfodiyo University Teaching Hospital, Sokoto, Nigeria \\ Email address: \\ danoaliyu@yahoo.com (A. Daniel) \\ ${ }^{*}$ Corresponding author \\ To cite this article: \\ Aliyu Daniel, Yikawe Semen Stephen. Clinical Profile of Epistaxis in Sokoto: A 12-Year Analysis. International Journal of \\ Otorhinolaryngology. Vol. 5, No. 1, 2019, pp. 20-23. doi: 10.11648/j.ijo.20190501.15
}

Received: March 7, 2019; Accepted: April 25, 2019; Published: June 11, 2019

\begin{abstract}
Epistaxis is bleeding from the Nose and Paranasal sinuses and could be a life threatening emergency requiring urgent attention. The aim is to determine the aetiological factors and highlight treatment modalities in a tertiary hospital in Northwestern Nigeria. This was a 12-year retrospective study of all patients managed with epistaxis between January 2000 and December 2011 in the otorhinolaryngology department of Usmanu Danfodiyo University Teaching Hospital, Sokoto. Ninetyfive patients were reviewed, out of which 61 [64\%] were males and 34 [36\%] were females. Age group 20-29 years had the highest prevalence [21.1\%]. The commonest aetiology was hypertension in $24.2 \%$ of patients followed by idiopathic $21.1 \%$, rhinosinusitis $20 \%$, trauma $14.7 \%$. Anterior nasal packing was the most common method of treatment [49.5\%]. Epistaxis is a common Otorhinolaryngological condition. Hypertension was the commonest cause in this study, with most cases seen in patients' aged $20-29$ years.
\end{abstract}

Keywords: Epistaxis, Hypertension, Anterior Nasal Packing

\section{Introduction}

Epistaxis, which is bleeding from the nose, is a common Otorhinolaryngological condition [1-3]. It can present as an emergency, or with mild recurrent bleeds, causing hemodynamic changes and being a source of great anxiety to the patients and their relatives [4]. About $60 \%$ of the general population will be affected by epistaxis in their lifetime, with only $6 \%$ requiring medical treatment, as most cases are selflimiting [1-5]. Epistaxis has been observed to account for 1 in 200 Emergency Department visits in the United States [6]. It accounted for $1.9 \%$ of all ENT cases seen in a tertiary hospital in Sokoto, Northwestern Nigeria over a five-year period $^{1}$. Epistaxis is more common in the Paediatric age group, with Males more affected than Females [7-8]. The nose is richly supplied by blood vessels from the external and internal carotid systems [4, 9]. The little's area, which is in the anterior inferior nasal septum, has the kiesselbach plexus formed by the Anterior ethmoidal, Sphenopalatine, Greater palatine and Superior labial arteries [10]. It is a common site of epistaxis. Other commonly encountered sites are Woodruff's plexus and Retrocollumella vein [4]. Most cases of epistaxis have no identifiable cause, but common aetiological causes are; trauma, infections, hypertension, blood disorders, iatrogenic causes and neoplasia [9, 11]. Studies have showed different treatment modalities in controlling epistaxis and these have since evolved with good outcome. In the past, simple effective approach such as pinching of the ala nasi and ligation of the external carotid artery in refractory epistaxis were used. However the advent of Hopkins rod telescopes in endoscopic ligation of Sphenopalatine artery has revolutionalised treatment of nasal bleeds with very high success rate $[2,3,10]$.

This study describes the clinical pattern of epistaxis observed in Usmanu Danfodiyo University Teaching Hospital Sokoto from January 2000 to December 2011.

\section{Materials and Methods}

This is a 12-year retrospective study of 95 patients seen in ENT department of Usmanu Danfodiyo University Teaching Hospital, Sokoto, Northwestern Nigeria from January 2000 to December 2011. Case folders of patients were obtained, relevant data, which included; demographics, nature of epistaxis, findings at nasal examination, duration of epistaxis before presentation and etiological Cause. Hematological 
investigations such as full blood counts, clotting profile and serum electrolyte were retrieved. Included also were findings on plain radiographs of the Paranasal sinuses, Bone marrow aspiration and Liver function tests. Modalities of Treatment offered and Outcome of treatment intervention. Excluded from the study were patients with postoperative nasal or paranasal bleeding. The data retrieved were analyzed using SPSS version 21 and the result presented in tabular and graphical forms.

\section{Results}

Out of the 95 patients seen, 61 [64\%] were males, while 34 [36\%] were females, with a Male: Female ratio of 1.8:1 [Figure 2]. Majority [21\%] of the patients seen were between the ages of $20-29$ years [figure 1]. Ages ranged from 5 to 81 years.

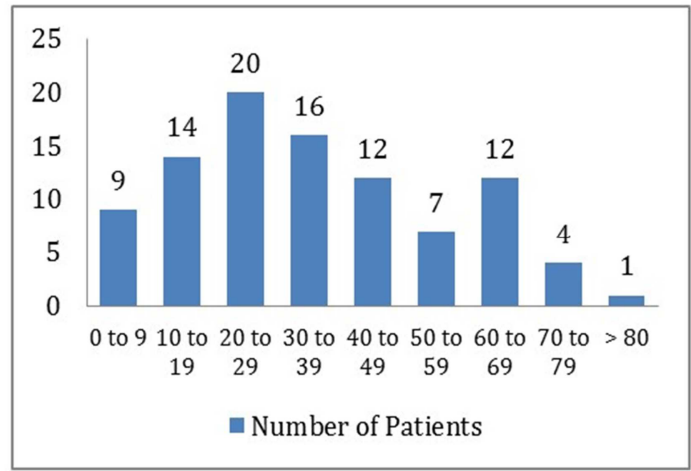

Figure 1. Age distribution of patients.

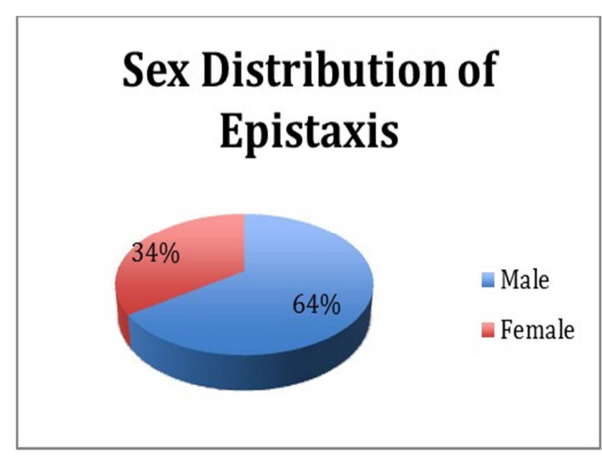

Figure 2. Distribution by sex.

In 43 [45\%] of the patients, epistaxis was Unilateral, while $52[55 \%]$ of them had bilateral epistaxis. Epistaxis was spontaneous in 78 [82\%] of the patients while it was induced in $17[18 \%]$ of the patients. Seventeen [18\%] of the patients had severe epistaxis necessitating blood transfusion. The commonest cause of Epistaxis seen in this study was hypertension [24.2\%], and in $21.1 \%$ of patients, the cause of epistaxis was unknown [Table 1].

Table 1. Causes of Epistaxis.

\begin{tabular}{lll}
\hline S/No & Cause & Number of patients \\
\hline 1 & Hypertension & 23 \\
2 & Idiopathic & 20 \\
3 & Rhinosinusitis & 19 \\
4 & Trauma & 14 \\
\hline
\end{tabular}

\begin{tabular}{lll}
\hline S/No & Cause & Number of patients \\
\hline 5 & Other bleeding disorders & 9 \\
6 & Disseminated intravascular coagulation & 4 \\
7 & Septal perforation & 3 \\
8 & Sickle cell disease & 2 \\
9 & Primary liver cell carcinoma & 2 \\
10 & Myeloproliferative disorder & 1 \\
11 & Chronic renal failure & 1 \\
\hline
\end{tabular}

\section{Treatment Modality}

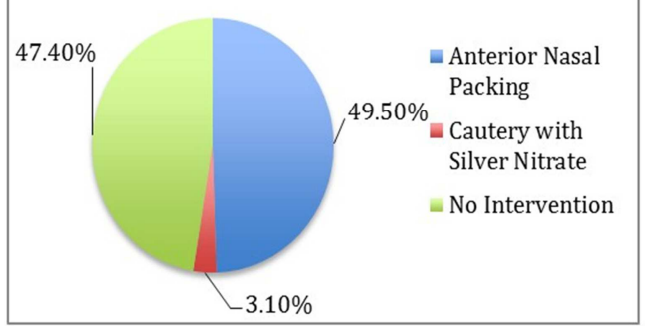

Figure 3. Treatment options applied to control epistaxis. Fourty-five [47.4\%] of the patients had spontaneous resolution of nosebleeds with no intervention.

Anterior nasal packing was offered to 47 [49.5\%] of the patients, $3[3.1 \%]$ had chemical cautery with sliver nitrate, while $45[47.4 \%]$ who did not have nasal packing or other interventions to control the bleeding [bleeding resolved spontaneously in these patients] were managed with antibiotics, haemantinics and other conservative measures [Figure 3]. No patient in this study had surgical intervention. Patients in this study whose epistaxis was due to an identified cause were offered treatment for the identified aetiology, including referrals to cardiologist [for hypertensives] and hematologist [for those with bleeding disorders]. Fifty-five [57.9\%] of patients came back for follow up in the clinic.

\section{Discussion}

Epistaxis is usually self limiting and patients don't present to the hospital for any form of treatment, even when they do, they are mostly seen be general purpose physicians and health workers often in primary or secondary healthcare centres [12]. The Otorhinolaryngologist sees a few. In this study only 95 patients were seen over a 12-year period. Iseh et al saw a total of 72 patients over a 5 -year period in the same center [1]. This might be due to the fact that there were few non - Otorhinolaryngologists that were willing to manage epistaxis at that time and as such most cases of epistaxis that presented to the hospital were referred to the ENT clinic. But with the proliferation of more specialties in the hospital and expansion in knowledge, more specialists are now willing to manage patients with epistaxis. Especially those without life threatening symptom.

Epistaxis is more common in males than in females [8, 1314]. In this study, the Male: Female ratio was 1.8:1. This agrees with studies conducted by Iseh et al, and Kodiya et al where they also observed a slight male preponderance $[1,8]$. In a retrospective study of patterns of hospital admissions with 
epistaxis of over twenty-six thousand patients over an 18-year period, Fishpool and Tomkinson observed that males had a higher proportion of hospital admissions for all age groups except the $10-14$ year age group [15]. This was further corroborated in a nationwide inpatient sample of patients with epistaxis in the US reported by Villwock and Jone, where they also observed a male preponderance of 53.4\% [16].

Though epistaxis is common among children, a bimodal age incidence has been described with peaks at $2-10$ years and $60-80$ years [4]. The modal age group in this study was $20-29$ years. In a study conducted in a tertiary health centre in Southwestern Nigeria, the modal age was 21 - 30 years, similar to the findings in this study [17]. Bimodal peaks were observed in studies conducted by Kodiya et al and Sogebi et al, Iseh et al however observed epistaxis to be more common among 0 - 10-year age group, while Anie et al, observed more cases above 60 years [1, 8-13].

The commonest cause of epistaxis in this study was hypertension $24.2 \%$. This is in contrast to other studies conducted in this country, where idiopathic causes were the commonest cause followed by trauma $[1,8,13,17]$. The association between epistaxis and hypertension is still being debated. Some authors belief that hypertension is common in acute epistaxis because of cofounding stress, and possible white coat phenomenon, but believe that a causation between epistaxis and hypertension is difficult to establish, while others believe that elevated blood pressure is a cause of epistaxis [1822]. In a systematic review of literature, Kikids and colleagues observed that arterial hypertension was higher in patients at the time of epistaxis when compared with the general population, most of the studies they reviewed agreed that there was a cross correlation between epistaxis and arterial hypertension, and they further suggested that epistaxis may lead to the diagnosis of a previously unrecognized arterial hypertension, they however could not find a causal relationship between epistaxis and arterial hypertension [20]. In an analysis of 133 patients with epistaxis by Terakura and colleagues, systolic blood pressure was found to be statistically significantly higher in patients with epistaxis, and on further multivariate analysis, systolic blood pressure was found to be an independent factor associated with epistaxis recurrence [21].

Trauma was common among patients with epistaxis in this study. Several studies have identified various forms of trauma as the most common cause of epistaxis [23-26]. Perhaps one of the reasons why trauma could be so common as an aetiological factor for epistaxis is because of the various entities grouped under nasal trauma when discussing epistaxis $[9,10]$. These include; road traffic accidents, nose picking, violent nose blowing or sneezing, assault, contact sports, iatrogenic, barotrauma and foreign bodies [9, 10].

Anterior nasal packing was offered to 47 [49.5\%] of the patients, while 45 [47.4\%] who did not have nasal packing were managed with antibiotics, haemantinics and other conservative measures. No patient in this study had surgical intervention.

Gabriel and colleagues observed similar findings [17]. In their study $26 \%$ of their patients had minimal treatment (observation, decongestants, ethamsylate) and 35\% had anterior nasal packing [17]. In the study conducted by Iseh et al, $34.7 \%$ of patients had no active intervention, while $34.7 \%$ of them had anterior nasal packing done [1]. Non-surgical methods have been observed to be effective in the treatment of most cases of epistaxis [27].

\section{Conclusion}

In our study, we observed a male preponderance, with the peak age incidence in the second and third decades with epistaxis. Hypertension a treatable clinical condition was the commonest cause of epistaxis. Therefore meticulous evaluation of patients to identify points of bleeds and etiological factors is mandatory for achieving effective management. All patients in this study were treated by nonsurgical means.

\section{References}

[1] Iseh KR, Muhammed Z. Pattern of epistaxis in Sokoto, Nigeria: A review of 72 cases. Ann Afr Med 2008; 7: 107-11.

[2] McClurg SW, Carrau R. Endoscopic management of posterior epistaxis: a review. Acta Otorhinolaryngol Ital 2014; 34(1): 1.

[3] Shargorodsky J, Bleier BS, Holbrook EH, Cohen JM, Busaba $\mathrm{N}$, Metson R, Gray ST. Outcomes analysis in epistaxis management: development of a therapeutic algorithm. Otolaryngol Head Neck Surg 2013; 149(3): 390-8.

[4] Nwaorgu OGB. Epistaxis: An Overview. Annals of Ibadan Postgraduate Medicine 2004; 1(2): 32-37.

[5] Purkey M, Seeskin Z, Chandra R. Seasonal variation and predictors of epistaxis. Laryngoscope. 2014; 124(9): 20282033.

[6] Pallin D, Chng Y, McKay M, Emond J, Pelletier A, Camargo C. Epidemiology of Epistaxis in US Emergency Departments, 1992 to 2001. Ann Emerg Med 2005; 46(1): 77-81.

[7] Fathy H, Ismail R, Mahmoud N, Abdel Wahab M. Recurrent epistaxis in children: When should we suspect coagulopathy? Egypt J Otolaryngol 2014; 30(2): 106.

[8] Kodiya AM, Labaran AS, Musa E, Mohammed GM, Ahmad BM. Epistaxis in Kaduna, Nigeria: A review of 101 cases. Afr Health Sci 2012; 12: 479-82.

[9] Kasperek ZA, Pollock GF. Epistaxis: an overview. Emerg Med Clin North Am 2013; 31(2): 443-54.

[10] Morgan DJ, Kellerman R. Epistaxis: evaluation and treatment. Prim Care: Clinics in Office Practice. 2014; 41(1): 63-73.

[11] Anie MT, Arjun GM, Andrews CJ, Vinayakumar AR. Descriptive epidemiology of epistaxis in a tertiary care hospital. Int $J A d v$ Med 2015; 2: 255-9.

[12] Rezende GL, Granjeiro RC, Furtado PL, Pinheiro GB, Nakanishi M. Is dry climate related with hospitals admissions for epistaxis. Int Arch Otorhinolaryngol. 2009; 13(2): 172-7.

[13] Sogebi OA, Oyewole EA, Adebayo OA. Epistaxis in Sagamu. Niger J Clin Pract 2010; 13: 32-6. 
[14] Parajuli R. Evaluation of Etiology and Treatment Methods for Epistaxis: A Review at a Tertiary Care Hospital in Central Nepal. Int J Otolaryngol 2015; 2015: 1-5.

[15] Fishpool SJ, Tomkinson A. Patterns of hospital admission with epistaxis for 26, 725 patients over an 18-year period in Wales, UK. Ann R Coll Surg Engl 2012; 94(8): 559-62.

[16] Villwock JA, Jones K. Recent trends in epistaxis management in the United States: 2008-2010. Otolaryngol Head Neck Surg 2013; 139(12): 1279-84.

[17] Gabriel OBamidele A. Epistaxis in Ido Ekiti, Nigeria: A 5-year review of causes, treatment and outcome. Sahel Med J 2013; 16(3): 107.

[18] Iqbal H, Bukhari ST, Hassan TU. Frequency of hypertension in the patients presenting with epistaxis in ENT Department, Nishtar Hospital, Multan. Available at http://www.pjmhsonline.com last assessed $17^{\text {th }}$ May 2017.

[19] Sarhan NA, Algamal AM. Relationship between epistaxis and hypertension: A cause and effect or coincidence? Journal of the Saudi Heart Association 2015; 27(2): 79-84.

[20] Kikidis D, Tsioufis K, Papanikolaou V, Zerva K, Hantzakos A. Is epistaxis associated with arterial hypertension? A systematic review of the literature. Eur Arch Otorhinolaryngol 2014; 271(2): 237-43.
[21] Terakura M, Fujisaki R, Suda T, Sagawa T, Sakamoto T. Relationship between blood pressure and persistent epistaxis at the emergency department: a retrospective study. $J \mathrm{Am}$ Soc Hypertens 2012; 6(4): 291-5.

[22] Gilyoma JM, Chalya PL. Etiological profile and treatment outcome of epistaxis at a tertiary care hospital in Northwestern Tanzania: a prospective review of 104 cases. BMC Ear Nose Throat Disord 2011; 11(1): 8.

[23] Eziyi JA, Akinpelu OV, Amusa YB, Eziyi AK. Epistaxis in Nigerians: A 3-year experience. East and Central African Journal of Surgery. 2009; 14(2): 93-8.

[24] Akinpelu O, Amusa Y, Eziyi J, Nwawolo C. A retrospective analysis of aetiology and management of epistaxis in a southwestern Nigerian teaching hospital. West Afr $\mathrm{J}$ Med $2009 ; 28(3)$.

[25] Arshad M, Ahmed Z, Ali L. Epistaxis: An experience with over 100 cases. Trauma. 2007; 17: 15-60.

[26] Khan A, Iqbal M, Zaman J. Evaluation of aetiology and efficacy of management protocol of epistaxis. J Ayub Med Coll Abbottabad. 2006; 18(4).

[27] Al Khtoum N, Al Roosan M. Evaluation of conservative measures in the treatment of epistaxis. Khartoum Medical Journal. 2012; 1(1). 